\title{
Recurrent Gliosarcoma
}

National Cancer Institute

\section{Source}

National Cancer Institute. Recurrent Gliosarcoma. NCI Thesaurus. Code C131209.

The reemergence of gliosarcoma after a period of remission. 